\title{
SPECIFICS IN THE FORMATION OF SUBSIDENCE TROUGHS IN THE KARVINA PART OF THE OSTRAVA-KARVINA COALFIELD WITH THE USE OF RADAR INTERFEROMETRY
}

\author{
Eva JIRÁNKOVÁ * and Milan LAZECKÝ
}

VŠB-Technical University of Ostrava, 17. Listopadu 15/2172, 70833 Ostrava-Poruba, Czech Republic

*Corresponding author's e-mail: eva.jirankova@vsb.cz

\begin{tabular}{l} 
ARTICLE INFO \\
\hline Article history: \\
Received 9 September 2015 \\
Accepted 13 March 2016 \\
Available online 29 March 2016 \\
\hline
\end{tabular}

Keywords:

Effects of undermining

Subsidence trough

Movement of surface points

SAR Interferometry

TerraSAR-X

\begin{abstract}
Deep extraction of minerals is accompanied by deformations of the strata overlying extracted coal seams. Deformations of overlying layers run up to the surface where a subsidence trough gradually forms. The movement of individual surface points is curvilinear, spatial and, in relation to the time pattern, not uniform. In some cases, during the formation of a subsidence trough, temporary uplifts of the surface occur. This paper gives a particular area in which uplifts of the surface occurred when the rigid overlying strata was disturbed. The character of deformations of the overlying rocks is evaluated on the basis of a comparison of the results of the measurement of subsidence of the surface using geodetic methods with the development of mined-out areas and with their extracted thickness. For specifying the time of failure of the overlying strata, also information obtained from a system of continuous monitoring of seismic events is used. The spatial extent of the subsidence trough is identified by satellite radar interferometry (InSAR) techniques applied to TerraSAR-X images. The subsidence wave was possible to detect using a short temporal difference of 11 days between satellite radar images. This shows the potential of short-temporal high resolution InSAR for monitoring of progress of subsidence troughs. A good knowledge of extents and shape of subsidence trough formation in time allows to verify values of parameters used for prediction purposes. Application of the short temporal InSAR appears very effective for spatio-temporal studies of the current subsidence trough development and helps understanding the physical process as well as identifying deviations from the behaviour expected by models.
\end{abstract}

\section{INTRODUCTION}

With the advance of mining to greater depths, the mechanism of failure of overlying rocks is changing relative to the experience gained from mining at shallow depths. At small depths of mining, the overlying strata were regularly disturbed and, from the point of view of the effects of undermining, the full effective area was usually extracted already by one coal face. Mining at depths greater than $700 \mathrm{~m}$ is accompanied by a much more complicated geomechanical situation; the full effective area is not mined out even by several neighbouring faces (OKD, Inc. 2015); overhangs of undisturbed Carboniferous rocks are formed in the overlying strata and a strutting arch is formed above the goaf. A regular failure of the overlying strata takes place only in those cases in which inter-seam rocks between an extracted seam and a previously extracted seam have such a small thickness that it does not enable a strutting arch to be formed, and under a prerequisite that the rigid roof broke through in the strata overlying the previously extracted seam (Jiránková, 2014).

With the advance of mining to greater depths, certain differences also occur when subsidence troughs are formed on the surface. Enormous concentrations of stress around the edges of the goaf in the overlying strata cause changes in the rock mass resulting in uplifts of the surface of the affected area. These uplifts of the surface can reach up to tens of centimetres. This paper describes the formation of a subsidence trough during the mining of coal seam 40 in the area of Block 7 of Mine Plant 1 of the Lazy site. The clarification of the dynamics of the subsidence trough is based on the current evaluation of measured subsidence of the surface, the miningtechnical parameters of extraction and seismological activity in the overlying strata. One of the main tasks when monitoring the effects of undermining is to determine the extent of the formed subsidence trough. Due to the limited possibilities of the measurement of heights of surface points using the method of levelling (Jiránková, 2014), it is necessary to use another method that provides information about the surface subsidence in time and area. There are several methods of remote sensing using, e.g., ground or aerial photogrammetry (Mikulenka et al., 2011; Kapica and Sládková, 2011), Lidar (Yu et al., 2011), etc., but they must target a certain area at a certain 
time. Another method that provides information about the surface subsidence in time and area is satellite radar interferometry. An advantage of this method is data availability from some of available satellite radar systems retroactively and the possibility of data processing for a far larger area than is the evaluated area (Perski et al., 2009). This is particularly advantageous in areas with extensive mining activity. The area of the subsidence trough formed as a result of the evaluated mining can come to the effects of mining activities in the surroundings. In these cases, it is advantageous to have information about the surface subsidence in an area wider than the area of the effect of the evaluated mining on the surface - the information that can be effectively provided by InSAR. This technique can detect not only an interpenetration of neighbouring subsidence troughs but also an overloading of surface that can be spreading to larger distance than the theoretical effective distance of the mining impact.

The objective of this study is to provide an additional information about subsidence trough development in the evaluated site and to detect a mining impact of its surroundings, using InSAR technology as a unique method for an effective spatiotemporal monitoring of subsidence.

\section{BASIC MINING-TECHNICAL INFORMATION OF THE EVALUATED SITE}

The area of concern of Block 7 of Mine Plant 1, Lazy site, is located in the Karvina part of the Ostrava-Karvina Coalfield (OKR), in the southern part of Orlova vicinity - see Figure 1 . The coal seams are extracted using the method of strike longwall mining with controlled caving. The first mined face in coal seam 40 was face 140702 with the average thickness $4.8 \mathrm{~m}$. The total strike length of the face is $848 \mathrm{~m}$ and the width of the face $120 \mathrm{~m}$. The mining of this face began in February 2012 and ended in February 2013. At the present time, the second face 140704 with the average thickness $5 \mathrm{~m}$ is also mined out. The total strike length of the face is $861 \mathrm{~m}$ and the width of the face is $200 \mathrm{~m}$. The second face was mined from July 2013 to October 2014. The third face 140706 in coal seam 40 is prepared for extraction. The previously mined coal seam 39 is found at an average depth of $685 \mathrm{~m}$ and coal seam 40 at an average depth of $740 \mathrm{~m}$ below the surface. The dip of layers in the area of Block 7 is variable. In the western part, the coal seams dip at $8^{\circ}$ towards $\mathrm{WNW}$ and, in the eastern part, at $7^{\circ}$ towards NNE. The complicated tectonic evolution has influenced the strata layering within Karvina part of Ostrava-Karvina Coalfield. In this area, both the extension and compression tectonic style is represented (Grygar and Waclawik, 2011; Waclawik et al., 2004). Coal seam 39 in the area is developed with the thickness $4-6 \mathrm{~m}$. The inter-seam between coal seams 40 and 39 has an average thickness of $55 \mathrm{~m}$ and is formed predominantly by fine- and medium-grained sandstone with

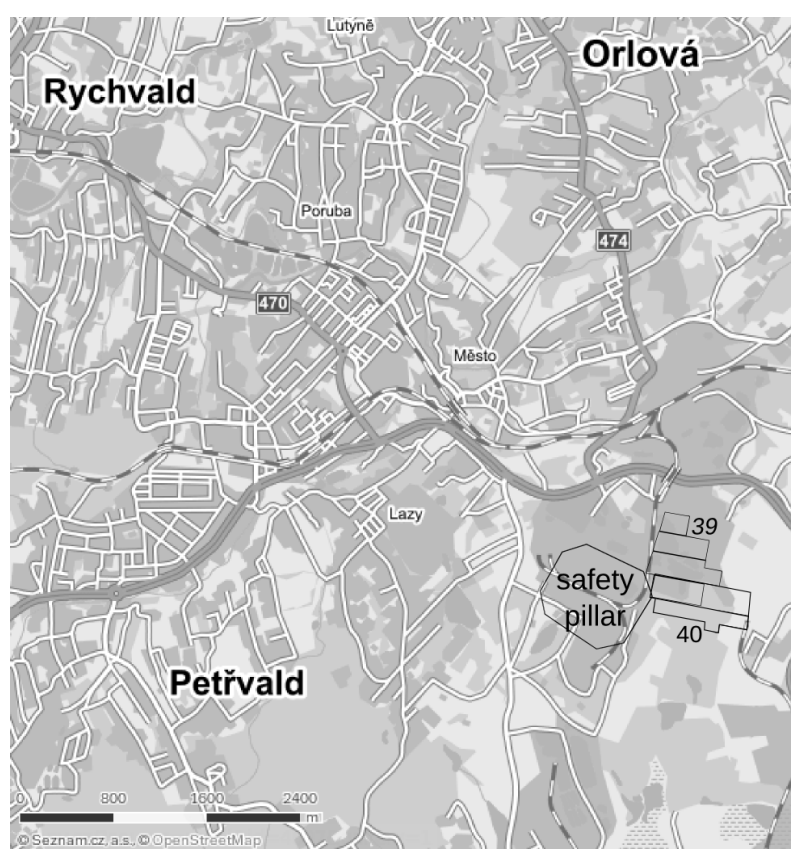

Fig. 1 Situation map of the location of interest seams 39 and 40 and safety pillar overlaid on map by (c) Seznam.cz, Inc.,

(c) OpenStreetMap.

intercalations of fine- to medium-grained conglomerate (Jiránková and Waclawik, 2013).

\section{GEODETIC MONITORING OF THE SURFACE}

As given above in the introduction, the results of the height measurements of surface points will be used for the explanation of the dynamics of the subsidence trough.

The first surface measurement of heights of surface points in the area of Block 7 was carried out on 15 March 2012 at the time of mining the first face 140702 in coal seam 40. The situation of the working face at the time of the first measurement is depicted in Figure 2. Subsequently measurements were carried out with an interval of two to six months. So far, the latest measurement of heights of surface points was made in February 2015. This paper gives only some of the accomplished measurements of the surface documenting the conclusions made and the interpretation of the results. The relative position of the mined faces and the surface points of an aligning base are depicted in Figure 2.

The measurement of heights of surface points was carried out using trigonometric levelling. The measurement was made using an instrument TCR 1201 Leica with accessories. The parameters of accuracy given by the manufacturer of this instrument are $1 \mathrm{~mm}$ for length measurement with a prismatic reflective system and 0.3 mgon for measurement of vertical angles. The length of the levelling traverse running in the line of the surface points was $1.9 \mathrm{~km}$, but for the reason of the reclamation of the area eight surface points were lost and thus also the length of the 


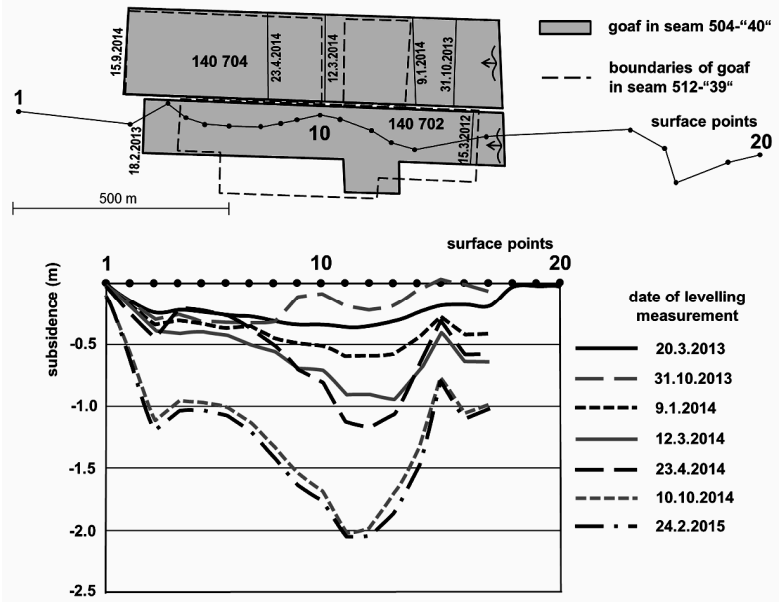

Fig. 2 Location of coal faces and surface points of the aligning base; subsidence in the line of the aligning base.

traverse has shortened to $1.2 \mathrm{~km}$. Presently, the surface observation station consists of twenty surface points. The heights of the points of the linear observation station were determined from two independent measurements. The starting point of the levelling traverse is point 1 , which is stabilized on a safety pillar of the central pits of Mine Plant 1, Lazy site. For each stage of measurement, the characteristics of accuracy were calculated; the mean kilometre error of the first stage of measurement from 15 March 2012 is $0.7 \mathrm{~mm}$. The mean kilometre error in the following stages of measurement ranged between 0.7 and $0.9 \mathrm{~mm}$.

Subsidence was calculated from the values of the measured heights of surface points, i.e. the differences of the heights of the same points over a certain period of time. The root mean square error (RMSE) of subsidence was determined as the root of the quadratic sum of the mean kilometre errors determined from the individual stages of measurement. The subsidence of the surface points with a risk of $5 \%$ is considered as proven if its value exceeds the determined confidence interval, i.e. twice the mean error of subsidence. The value of the confidence interval ranges between 3.3 and $3.8 \mathrm{~mm}$.

\section{SATELLITE RADAR INTERFEROMETRY}

For monitoring the effects of undermining and particularly for determining the extent of the affected area on the surface, the method called satellite radar interferometry (InSAR) appears as suitable (Lazacký and Jiránková, 2013). It enables height changes on a monitored territory of an area of usually several tens of thousands of hectares to be evaluated. Satellite radars (SAR) do not measure in the direction perpendicular to the Earth for technological reasons, but scan with an inclination at the so-called angle of incidence - the measured values of deformations thus relate to the line of the satellite view (line-of-sight, LOS) and this can concern both vertical and horizontal movements where detection sensitivity is several times higher for vertical movements, for example for subsidence (Samieie-Esfahany et al., 2009).

In case of a sufficient number of images so that they can enable error components to be sufficiently reliably modelled, such as the effect of the atmosphere or height changes, the accuracy of InSAR is confirmed to be better than $1 \mathrm{~mm} /$ year (Ferretti et al., 2007). About 20 images is given as often a sufficient number of images for older systems, e.g. Envisat (Colesanti et al., 2003); in case of more advanced ones (e.g. TerraSAR-X), less images are sufficient for the reason of a higher stability of the satellite orbital path, higher resolution, etc.; in contrast, with a higher number of images, it is possible to reliably evaluate movements with accuracy better than $0.1 \mathrm{~mm} /$ year in LOS (Rucci et al., 2012).

The largest problem for monitoring subsidence on the territory of the OKR using the InSAR method is particularly the rate of the local subsidence often exceeding the maximum detection capability of the method. Because SAR radars measure movements within the wavelength used and SAR images have certain spatial resolution, it is possible to quantify the detection limit $\Delta \mathrm{D}$ in ideal conditions (Hanssen, 2001). This limit is practically lower in areas covered by dense vegetation, the movement and growth of which is also detected in SAR images.

For the evaluation of subsidence in the area of Block 7 of Mine Plant 1, Lazy site, 17 images of TerraSAR-X from a period of October 2013 to May 2015 were used, in an imaging periodicity of 33 days (except for one pair with a time lapse of 11 days in March 2014). The spatial resolution of the data was around $1 \times 3 \mathrm{~m}$. The theoretical detection limit of the satellite TerraSAR-X is $\Delta \mathrm{D}_{\mathrm{TSX}}=15.5 \mathrm{~mm} / \mathrm{m}$ in LOS between every two images (Lazecký, 2011). Already this limit in a time range of 33 days is lower than the expected movements of the monitored area. The only pair available with a lapse of only 11 days evaluates the subsidence of the monitored area in Figure 3 with a maximum value of $110 \mathrm{~mm}$ (in LOS) relative to the margin of the subsidence trough. This figure is based on a simple differential interferometry (DInSAR) processing where phase of two radar images is combined interferometrically and a SRTM digital elevation model is used for removal of height-induced phase (Kampes et al., 2003).

In the case of DInSAR combinations of the other images, the detected movement becomes underevaluated and the signal disappears due to vegetation. Therefore, it was possible to use the whole set of images only for identifying the boundaries of the subsidence trough. This was done by using an advanced multi-image technique known as Quasi Permanent Scatterers InSAR (Quasi-PS InSAR) implemented in SARPROZ software (Perissin et al., 2007). This method evaluated subsidence only for selected suitable points showing certain spatio- 


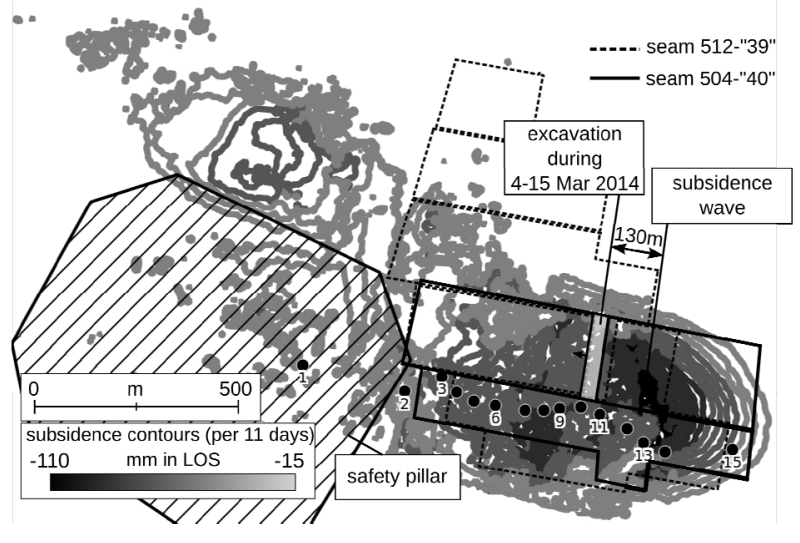

Fig. 3 Subsidence wave identified directly in the subsidence trough thanks to the short time base between images (11 days) using DInSAR method. The selected contours record movements in LOS are in a range of $1.5-11 \mathrm{~cm}$ in the period of $4-15$ March 2014.

temporal coherence (Quasi-PS points) on the basis of filtered interferograms. The evaluated values of the cumulative subsidence of these points during the monitored period in LOS were recomputed into theoretical values of vertical subsidence, neglecting potential horizontal movements (Hanssen, 2001), and interpolated for the whole area using the Inverse Distance Weighting method. The interpolated raster then served for the creation of contours estimating cumulative subsidence shown in Figure 4.

It is assumed by this technique of processing that movements at the sites outside Quasi-PS points are strongly under-evaluated or even neglected. Thus, only the contours connecting the places with cumulative subsidence to $20 \mathrm{~mm}$ were selected for Figure 4 (relative to a reference point selected outside the undermined area). This boundary value is relatively reliable in relation to the distribution of Quasi-PS points and their values of subsidence. These contours delineate the areas in which significant subsidence occurs.

The Quasi-PS InSAR method was used to evaluate height changes at a distance of about $65 \mathrm{~m}$ from the location of the starting point of the levelling traverse (surface point 1). The evaluated time series of vertical movement of this point according to InSAR processing is given in Figure 5 (LOS values were recomputed into vertical direction, assuming no horizontal movements). It can be judged that the starting point itself of the levelling traverse will be affected by a similar trend of subsidence. In relation to possible inaccuracies in processing (among others, Quasi-PS InSAR uses considerably spatially filtered data), it is necessary to assess the graph of movement of this point only tentatively.

The velocity of vertical movement at this site was estimated as $-21.5 \mathrm{~mm} /$ year, with a standard deviation of $1.1 \mathrm{~mm} /$ year, from the dataset spreading

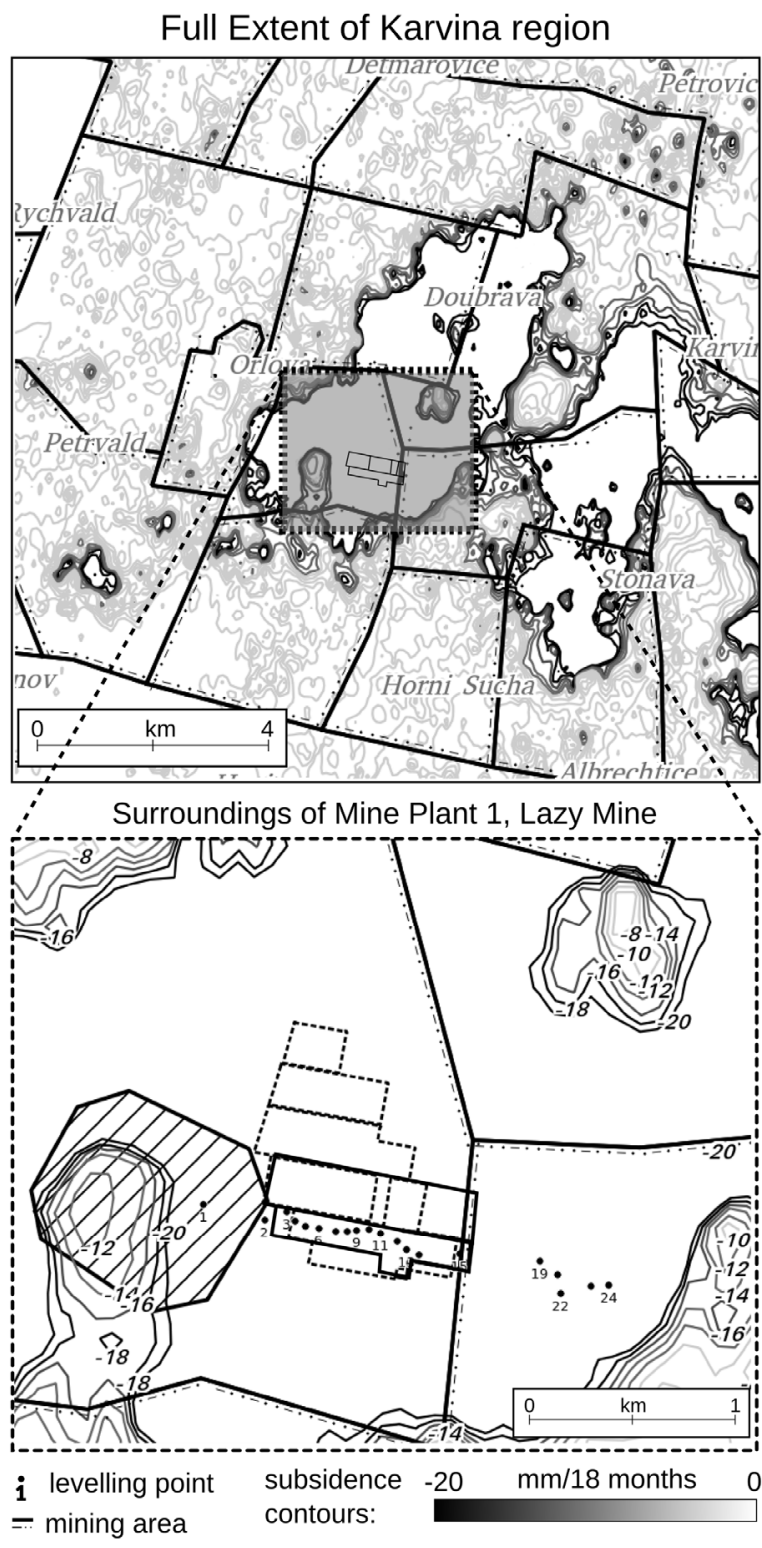

Fig. 4 Cumulative subsidence between October 2013 and May 2015, interpolation based on the Quasi-PS InSAR results. The described area shows subsidence trough extents of the whole Karvina region (upper figure) and a crop to surroundings of Mine Plant 1 of Lazy Mine (lower). The selected contours of down to $-20 \mathrm{~mm}$ show reliable boundaries of active subsidence troughs.

October 2013 to May 2015. The reliability of the value should be confirmed by comparison with other geodetic data. However for this site, the starting point is monitored only once per year with the last measurement being on $4^{\text {th }}$ March, 2014 (height was $255.469 \mathrm{~m}$ ) and the previous one on $20^{\text {th }}$ March, 2013 (height was $255.569 \mathrm{~m}$ ) (OKD Inc., 2015). These dates overlap with InSAR data in $\sim 5$ months. A linear interpolation from the geodetic measurements would show subsidence of $4.3 \mathrm{~cm}$ during this period, supposing InSAR evaluation $(6 \mathrm{~mm})$ being strongly 


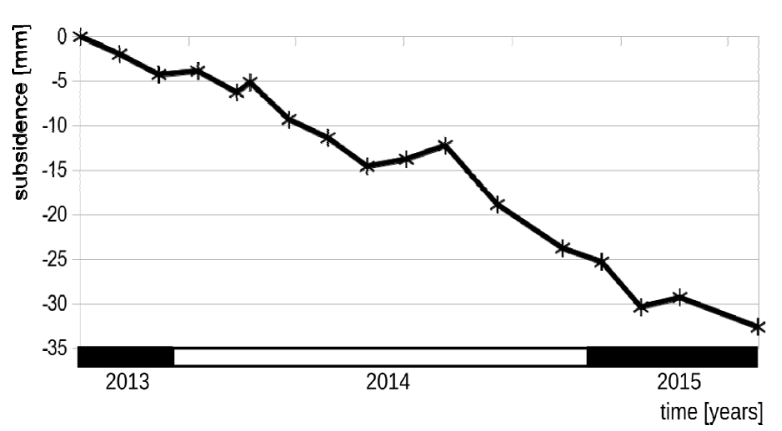

Fig. 5 Time series of subsidence (recomputed from LOS assuming no horizontal movement) in the close vicinity of point 1 (i.e. the starting point of the levelling traverse).

underestimated. On the other hand, there was strong mining activity during 2013 in the neighbourhood therefore the linear trend of subsidence cannot be assumed and the comparison between InSAR estimations and geodetic measurements cannot be performed reliably.

\section{INTERPRETATION OF THE RESULTS}

It is necessary to view the rigid overlying strata as a layered inhomogeneous girder composed of variously thick and differently rigid layers, which are disturbed by a complicated system of tectonic fractures (Jiránková, 2010; Jiránková, 2012).

The evaluation of failure of the rigid overlying strata of coal seam 40 shows that the breakthrough of the rigid overlying strata at the time of mining face 140702 did not occur. After the end of mining face 140702 , the surface measurement of heights was used to identify the largest subsidence being $352 \mathrm{~mm}$, which corresponds to the formed strutting arch above the goaf. At the time of mining face 140702 , no significant seismological events were recorded. The width of the face at the beginning of mining was $120 \mathrm{~m}$; after about $250 \mathrm{~m}$ of the strike length was mined out, the face was widened to $195 \mathrm{~m}$ and then shortened to $120 \mathrm{~m}$ in width. The total strike length of the face was $848 \mathrm{~m}$. The parameters of the first face do not reach the width of the goaf at the probable time of breakthrough of the rigid overlying strata of coal seam 40, which could be expected on the basis of experience gained from other evaluated area (Jiránková, 2012). The mining of the second face 140704 was accompanied by a much higher seismological activity. With the beginning of mining (on 29. 7. and 27.8.), two events were classified as mine shocks; the energy of these events was $1.7 \cdot 10^{6} \mathrm{~J}$ and $8.7 \cdot 10^{5} \mathrm{~J}$. At the time of mining the second face, the rigid overlying strata of coal seam 40 broke through approximately after $200 \mathrm{~m}$ of the strike length of face 140704 had been mined out. Based on the parameters of the goaf, the width of the goaf at the time of breakthrough was determined at $250 \mathrm{~m}$.

The formation of the subsidence trough was significantly affected by pillars left in place and the edges of the goaf in the previously mined coal seam 39. As given above, after the first face 140702 in coal seam 40 was mined out, the largest subsidence was measured on the surface with the value $352 \mathrm{~mm}$ approximately above the centre of gravity of the goaf and the subsidence trough had a regular bowl-like shape (Fig. 2, the subsidence curve as on 20 March 3 2013). During mining the second face 140704 in coal seam 40, short-term uplifts of the surface occurred when the subsidence trough was formed. The first uplifts of the surface were detected from height measurement on 31 October 2013 (Fig. 2) in the areas of the edge projection and a pillar left in place in coal seam 39. During mining the second face 140 704, the rigid overlying strata broke through, as given above. The results of measurement of the surface on 9 January 2014 show that the area of uplifts around surface point 10 dropped and the slope of the subsidence trough has taken the shape corresponding to the theoretical assumption. The opposite slope of the subsidence trough remains deformed in relation to shape in the place of the edge projection of the goaf of the previous mining in coal seam 39. Deformations of the shape of the slope of the subsidence trough in this place are evident in all results of the following height measurements of the surface, see Figure 2. It is necessary to point out that the distances of surface points in the graphic depiction of subsidence of surface points in Figure 2 do not correspond with the distances of points of the aligning base; it is also evident in the graphic depiction of the relative position of goafs and measuring points that the aligning base is curved.

Short-term uplifts of the surfare also occurred at the time of mining after the rigid overlying strata of the evaluated coal seam had broken through. Immediately after the passage of the working face beneath the pillar left in place, an area of uplifts of the surface formed in the foreland of the face, as is evident from the results of measurement on 23 April 2014 and from comparison with the results of the previous measurement made on 12 March 2014. During subsequent mining, this area of uplifts dropped and only a deformation of the shape of the subsidence trough in the place of the edge projection of previous mining in coal seam 39 is evident from measurements carried out after the end of mining face 140704 on 10 October 2014 and 24 February 2015.

Deformations of the shape of the subsidence trough will probably not have a permanent character. The mining of the planned third face in coal seam 40 will cause a new rearrangement of rocks overlying the already mined-out faces and the breaking of overhangs of Carboniferous rocks. As a consequence of this, a gradual formation of the subsidence trough in terms of not only its extent, but also its shape can be expected. One of the parameters necessary to define a time function was identified by measuring the distance between the edge of excavation and the peak of subsidence (that is around $130 \mathrm{~m}$ ). The time 
function is a part of the theoretical computation of surface subsidence. Good knowledge of dynamics of subsidence trough allows an early protection of surface objects against dangerous effects of undermining. From the graphical processing of radar data, short-temporal dynamics of surface subsidence can be observed - Figure 3 presents the state of the coal face between the radar data acquisition times: a so-called subsidence wave is visible as the place of the highest rate of subsidence within the time period of 11 days. Figure 4 displays the extent of subsidence trough in period since October 2013 until May 2015, not only within evaluated area but also in wider surroundings. This processing is advantageous mainly for assessment of influence of surrounding excavation on the slope of subsidence trough of the area under evaluation. There is also a deformation of safety pillar of the central pits of Mine Plant 1 (Lazy site) visible in Figure 4. The subsidence of close surroundings of the starting point of the levelling traverse is represented graphically in Figure 5, the amount of subsidence within the period between October 2013 to May 2015 is $33 \mathrm{~mm}$. Until now, the height of the starting point of the levelling traverse used to be connected from area that wasn't undermined once per 2-3 years, using mine district levelling. Results from radar interferometry allow correcting the height of the starting point directly for the date of levelling measurements.

\section{CONCLUSIONS}

Movements and deformations of the surface are a consequence of changes that take place inside the rock mass. This paper describes a case where uplifts of the surface occurred during the formation of a subsidence trough, gives causes of this phenomenon and also interprets the state of failure of the rigid overlying strata of the evaluated coal seam. Uplifts of the surface are constituent part of the dynamic development of subsidence trough and are of a temporary character. Due to the access difficulty of geodetic measurements of the surface, the application of radar interferometry data has been proposed. The advantage of this method is the possibility of spatiotemporal evaluation of subsidence trough.

We have tested a high resolution X-band SAR data for application in determining the extent of the subsidence trough in the area. The available dataset was formed by a moderate number of images within temporal distribution of every 33 days, with one exception of a pair with 11 days difference. We show and conclude that for a reliable monitoring of rapid subsidence trough formation, typical of OKR area, a higher number of images with a shorter time base should be used. The base with a range of 11 days (the minimum possible time interval of the TerraSAR-X satellite) has shown as sufficient to detect the subsidence wave during March 2014. Longer temporal intervals (33 days) are affected by InSAR decorrelation due to vegetation growth changes as well as due to high rate of subsidence, exceeding detection limits of TerraSAR-X. Using these long temporal combinations, real rates of subsidence could not be quantified in the center of subsidence trough. However, the multi-image InSAR techniques show a significant added value of the InSAR method for subsidence monitoring although using data of longer temporal frequency. Thanks to its unique sensitivity to movements of subtle rates of even few millimeters per year, the multi-temporal InSAR allows the spatial boundaries of subsidence troughs to be precisely evaluated. A good knowledge of extents and shape of subsidence trough formation in time allows to verify values of parameters used for prediction purposes.

\section{ACKNOWLEDGMENTS}

This paper has been elaborated in the framework of the project New creative teams in priorities of scientific research, reg. no. CZ.1.07/2.3.00/30.0055, supported by Operational Programme Education for Competitiveness and co-financed by the European Social Fund and the state budget of the Czech Republic. This work was supported by the European Regional Development Fund in the IT4 Innovations Centre of Excellence project (CZ.1.05/1.1.00/02.0070). This work was supported by project called „Disaster management support scenarios using geoinformation technologies“" No VG20132015106, program Safety Research promoted by Ministry of Interior, Czech Republic, and by the European Regional Development Fund in the IT4Innovations Centre of Excellence project (CZ.1.05/1.1.00/02.0070) and by project NPU II LQ1602 „IT4Innovations excellence in science“. The data were achieved within the DLR project LAN1130, (c) DLR 2015. Authors are grateful to Dr. Daniele Perissin for offering usage of SARPROZ software for processing the data.

\section{REFERENCES}

Colesanti, C., Ferreti, A., Novali, F., Prati, C., and Rocca, F.: 2003, SAR monitoring of progressive and seasonal ground deformation using the permanent scatterers technique, IEEE Transactions on Geoscience and Remote Sensing, No. 41, 1685-1701.

Ferretti, A., Giuliano, S., Riccardo, B., Alessandra, B., Sergio, M., Fabrizio, N., Claudio, P. and Fabio, R.: 2007, Submillimeter accuracy of InSAR time series: Experimental validation. IEEE Transactions on Geoscience and Remote Sensing, 45, No. 5, 1142-53. DOI:10.1109/TGRS.2007.894440

Grygar, R. and Waclawik, P.: 2011, Structural-tectonic conditions of Karvina Subbasin with regard to its position in the apical zone of Variscan accretion wedge. Acta Montan. Slovaca, 16, No. 2, 159-175.

Hanssen, R.F.: 2001, Radar Interferometry: Data Interpretation and Error Analysis. Dordrecht, Kluwer Academic Publishers, 275 pp.

Jiránková, E. and Waclawik, P.: 2013, Spatio-temporal analysis of the influence of mining on the surface - A case study from the Ostrava-Karvina Coal Field. 
ISRM International Symposium (EUROCK), Wroclaw, 739-743.

Jiránková, E.: 2010, Assessment of rigid overlying strata failure in face mining. Cent. Eur. J. Geosci., 2, No. 4, 524-530. DOI: $10.2478 / \mathrm{v} 10085-010-0014-7$

Jiránková, E.: 2012, Utilisation of surface subsidence measurements in assessing failures of rigid strata overlying extracted coal seams. Int. J. Rock Mech. Min. Sci., 53, 111-119.

DOI: $10.1016 /$ j.ijrmms.2012.05.007

Jiránková, E.: 2014, The method of assessment of failure of the rigid strata overlying extracted coal seams with support of geoinformation technologies. The Technical University of Košice, Košice, 75 pp.

Kampes, B. M., Hanssen, R. F. and Perski, Z.: 2003, Radar interferometry with public domain tools. Fringe Workshop, Frascati, 6 pp.

Kapica, R. and Sládková, D.: 2011, Photogrammetric analysis of objects in undermined territories. Geodesy and Cartography, 37, No. 2, 49-55. DOI:10.3846/13921541.2011.586440

Lazecký, M. and Jiránková, E.: 2013, Optimization of satellite InSAR techniques for monitoring of subsidence in the surroundings of Karviná Mine: Lazy Plant. Acta Geodyn. Geomater., 10, No. 1 (169), 6165. DOI: $10.13168 /$ AGG.2013.0005

Lazecký, M.: 2011, Monitoring of Terrain Relief Changes using Synthetic Aperture Radar Interferometry: Application of SAR Interferometry Techniques in a Specific Undermined Ostrava-Karviná District. PhD thesis, VŠB-TU Ostrava, Ostrava, 176 pp.

Mikulenka, V., Kapica, R. and Sládková, D.: 2011, The potential of photogrammetry for object monitoring in undermined areas. Acta Montan. Slovaca, 16, No. 4, 262-269.

OKD, Inc.: 2015, Private communication.
Perissin, D., Ferretti, A., Piantanida, R., Piccagli, D., Prati, C., Rocca, F., Rucci, A. and de Zan, F.: 2007, Repeatpass SAR interferometry with partially coherent targets. Fringe Workshop, Frascati, 7 pp.

Perski, Z., Hanssen, R., Wojcik, A. and Wojciechowski, T.: 2009, InSAR analyses of terrain deformation near the Wieliczka Salt Mine, Poland. Engineering Geology, 106, No. 1-2, 58-67. DOI: 10.1016/j.engeo.2009.02.014

Rucci, A., Ferretti, A., Monti Guarnieri, A. and Rocca, F.: 2012, Sentinel 1 SAR interferometry applications: The outlook for sub millimeter measurements. Remote Sensing of Environment, 120, No. 5,156-163. DOI: $10.1015 /$ j.rse.2011.09.030

Samieie-Esfahany, S, Hanssen, R., van Thienen-Visser, K. and Muntendam-Bos. A.: 2009, On the effect of horizontal deformation on InSAR subsidence estimates. Fringe Workshop, 677, 7 pp.

Waclawik, P., Ptáček, J., and Grygar, R.: 2013, Structural and stress analysis in mining practice in the Upper Silesian Coal Basin. Acta Geodyn. Geomater., 10, No. 2(170), 255-265. DOI: $10.13168 /$ AGG.2013.0026

Yu, H., Lu, X., Cheng, G. and Ge, X.: 2011, Detection and volume estimation of mining subsidence based on multi-temporal LiDAR data. 19th International Conference on Geoinformatics, 1-6.

DOI: 10.1109/GeoInformatics.2011.5980892 